\title{
AVALIAÇÃO DE CULTIVARES DE MILHO VERDE EM PARIQUERA-AÇU (1)
}

\author{
ISSAO ISHIMURA $(2,5)$, KIYOSHI YANAI $\left(^{2}\right)$, \\ EDUARDO SAWAZAKI $\left({ }^{3,5}\right)$ e MASSAHARU NODA $\left({ }^{4}\right)$
}

\begin{abstract}
RESUMO
Os cultivares de milho Cargill 742, Cargill 408, Cargill 511, Cargill 501, Agroceres 162, Pioneer X 307, IAC Phoenyx 1918, IAC Phoenyx o2 1313, IAC Maya XIX e BR 126 foram avaliados em duas épocas, em plantios de inverno (maio e junho de 1983) na Estação Experimental de Pariquera-Açu, SP, com o objetivo de identificar os melhores para a produção de milho verde. Foram estudadas as seguintes características agronômicas: estande fìnal; número e total de espigas comerciáveis; peso de espigas com palha, comerciáveis e total; índice de espigas (número de espigas comerciáveis/estande final) e peso médio de espigas comerciáveis. Os cultivares se diferenciaram quanto à populaçầo final de plantas; índice de espigas; resistência a Helminthosporium turcicum Pass.; ciclo do plantio à colheita, e produtividade: o Cargill 742 e o Cargill 408 foram os mais produtivos, superando o Agroceres 162, e mostraram ainda menor incidência de Helminthosporium turcicum, maior índice de espigas e precocidade. As condições climáticas foram atípicas, desfavoráveis à cultura do milho, provocando baixo nível de produtividade, que ainda foi lucrativo.
\end{abstract}

Termos de indexação: milho verde; cultivares Cargill 408, 501, 511 e 742; Agroceres 162, Pioneer X 307, IAC Phoenyx 1918, Phoenyx o2 1313, Maya XIX e BR 126.

(1) Trabalho apresentado no XXIV Congresso Brasileiro de Olericultura e I Reuniāo Latino-Americana de Olericultura, Jaboticabal, SP, Brasil, em 16-21 de julho de 1984. Recebido para publicação em 6 de novermbro de 1984.

(2) E.E. de Pariquera-Açu, Instituto Agronômico (IAC), Caixa Postal 28, 13001 Campinas (SP).

(3) Seção de Milho e Cereais Diversos, IAC.

(4) Japan International Cooperation Agency, JCA/CEDAVAL.

(5) Com bolsa de suplementação do CNPq. 


\section{INTRODUÇĀO}

O milho consumido no ponto de milho-verde, após cozimento da espiga ou na forma de pratos como pamonha, curau, sorvetes, bolos, é constituído, em sua maior parte, de endosperma normal, de grãos dentados amarelos. Milhos especiais, como opaco-2, doce e superdoce, mutantes de endosperma, são pouco utilizados, apesar de apresentarem melhores qualidades para consumo após o cozimento da espiga.

O milho-verde encontrado à venda nas feiras e supermercados apresenta variaçōes nos tipos de grāo (dentados a duros), além de grande desuniformidade no ponto de maturação. Isso mostra que o produtor de milho-verde desconhece os cultivares mais apropriados. A falta de informações sobre o comportamento dos cultivares para produçāo de milho verde, principalmente em plantio fora da época tradicional, contribui para essa situação.

Em Pariquera-Açu, no Vale do Ribeira, SAWAZAKI et alii (1979) obtiveram bons resultados ccm o plantio de inverno de diversos tipos de cultivares de milho avaliados no ponto de verde. A região possui condições favoráveis de temperatura e precipitação para o cultivo do milho durante o inverno (março a julho). Nesse período, a regiāo que mais produziu milho verde em 1983, em São Paulo, foi Presidente Prudente (BOLETIM INFORMATIVO ANUAL, 1983), com a desvantagem de um custo de produção maior, devido à necessidade do uso de irrigação e maior custo de transporte. Com o objetivo de incrementar a produção de milho verde no Vale do Ribeira, diversos trabalhos foram conduzidos visando ao desenvolvimento de tecnologia apropriada às condições locais (ISHIMURA et alii, 1984 e SAWAZAKI et alii, 1979). Seguindo essa meta, foi realizado o presente trabalho, cujo objetivo foi a avaliação de dez cultivares de milho, com características desejáveis para utilização no estádio de verde, em duas épocas de plantio durante o inverno.

\section{MATERIAL E MÉTODOS}

Foram utilizados dez cultivares de milho do tipo de grãos dentados e de endosperma amarelo, sendo um híbrido simples, Cargill 742; cinco hibridos duplos: Cargill 408, Cargill 511, Cargill 501, Agroceres 162 e Pioneer X 307; dois hibridos intervarietais: IAC Phoenyx 1918 e IAC Phoenyx o2 1313; e duas variedades: IAC Maya XIX e BR 126.

Utilizou-se o delineamento experimental de blocos ao acaso com quatro repetições. Cada parcela foi constituída de três linhas de $5 \mathrm{~m}$. O espaçamento foi de $0,8 m$ entre linhas por $0,2 m$ entre covas. As duas linhas laterais foram consideradas como bordadura. Os ensaios foram plantados em 3/5/83 (1ª época) e 24/6/83 (2 época), na área do pôlder experimental do Centro de Desenvolvimento Agricola do Vale do Ribeira (CEDAVAL). No sulco de plantio, foi utilizada a 
formulação 4-14-8 de NPK, na base de 375kg/ha; aplicado o inseticida Aldicarb $5 \%$ granulado (Temik) na dose de $8 \mathrm{~g} / 5 \mathrm{~m}$, e semeadas duas sementes por cova, para posterior desbaste, deixando-se uma planta por cova. Após o plantio, foi aplicado o herbicida Simazine $80 \%$ (Gesatop 80 ) para controle de envas daninhas. $\mathrm{Na}$ adubação de cobertura, foi aplicada uréia, $100 \mathrm{~kg} / \mathrm{ha}$, aos 28 e 34 dias após a emergência, respectivamente, para $1^{\mathrm{a}}$ e $2^{\mathrm{a}}$ época. Para evitar problemas com o acamamento, efetuou-se a amontoa.

A colheita do milho no estádio de verde, na $1^{\text {a }}$ época, foi feita em três etapas: 31/8/83, para os cultivares Cargill 742 , Cargill 501, Cargill 511 e Cargill 408; 6/9/83, para o cultivar Pioneer $X 307$ e em 14/9/83 para os cultivares BR 126, IAC Maya XIX, IAC Phoenyx 1918, IAC Phoenyx o2 1313 e Agroceres 162. $\mathrm{Na} 2^{\text {a }}$ época, as datas da colheita foram: 25/10/83, para o Pioneer $X 307$, Cargill 742, Cargill 408, Cargill 501 e Cargill 511; 5/11/83, para BR 126 e Agroceres 162, e 7/11/83, para o IAC Phoenyx 1918, IAC Phoenyx o2 1313 e IAC Maya XIX. Nos dois ensaios foram coletados dados relativos ao estande final, número de espigas, tipo comercial e total; peso de espigas com palha, tipo comercial e total. $\mathrm{Na}$ segunda época, foram dadas notas para o ataque de Helminthosporium turcicum Pass., segundo a escala de ELLIOT \& JENKINS (1946). A partir desses dados, foram obtidos o índice de espiga (número de espigas comerciáveis/estande final) e o peso médio de espiga (peso de espigas comerciáveis dividido pelo seu número). Considerou-se como espiga comerciável apenas aquela de tamanho maior que a metade do comprimento das espigas maiores.

Foi feita a análise estatística dos dados por época e também a conjunta das duas épocas. Para a comparação de médias foi empregado o teste de Duncan ao nivel de $5 \%$.

\section{RESULTADOS E DISCUSSÃO}

Os resultados obtidos com a primeira e segunda época, constam, respectivamente, dos quadros 1 e 2 . Na primeira época, o estande final variou de 37.500 a 55.625 plantas/hectare, com o Cargill 408 apresentando a maior população, não diferindo estatisticamente do Cargill 742 e do Pioneer $X 307$. Na segunda época, a populaçăo de plantas foi menor, variando de 22.500 a 50.625 plantas/hectare, tendo maior estande o Agroceres 162, não diferindo, estatisticamente, do Cargill 408 e Cargill 742. O Agroceres 162 foi o único cultivar que teve maior população de plantas em comparação à primeira época. A maior redução do estande ocorreu no híbrido Pioneer $X$ 307, que teve a menor populaçāo, diferindo estatisticamente dos demais.

As diferenças observadas na população final de plantas entre cultivares são conseqüências de fatores ligados à qualidade da semente e ao genótipo dos cultivares. 


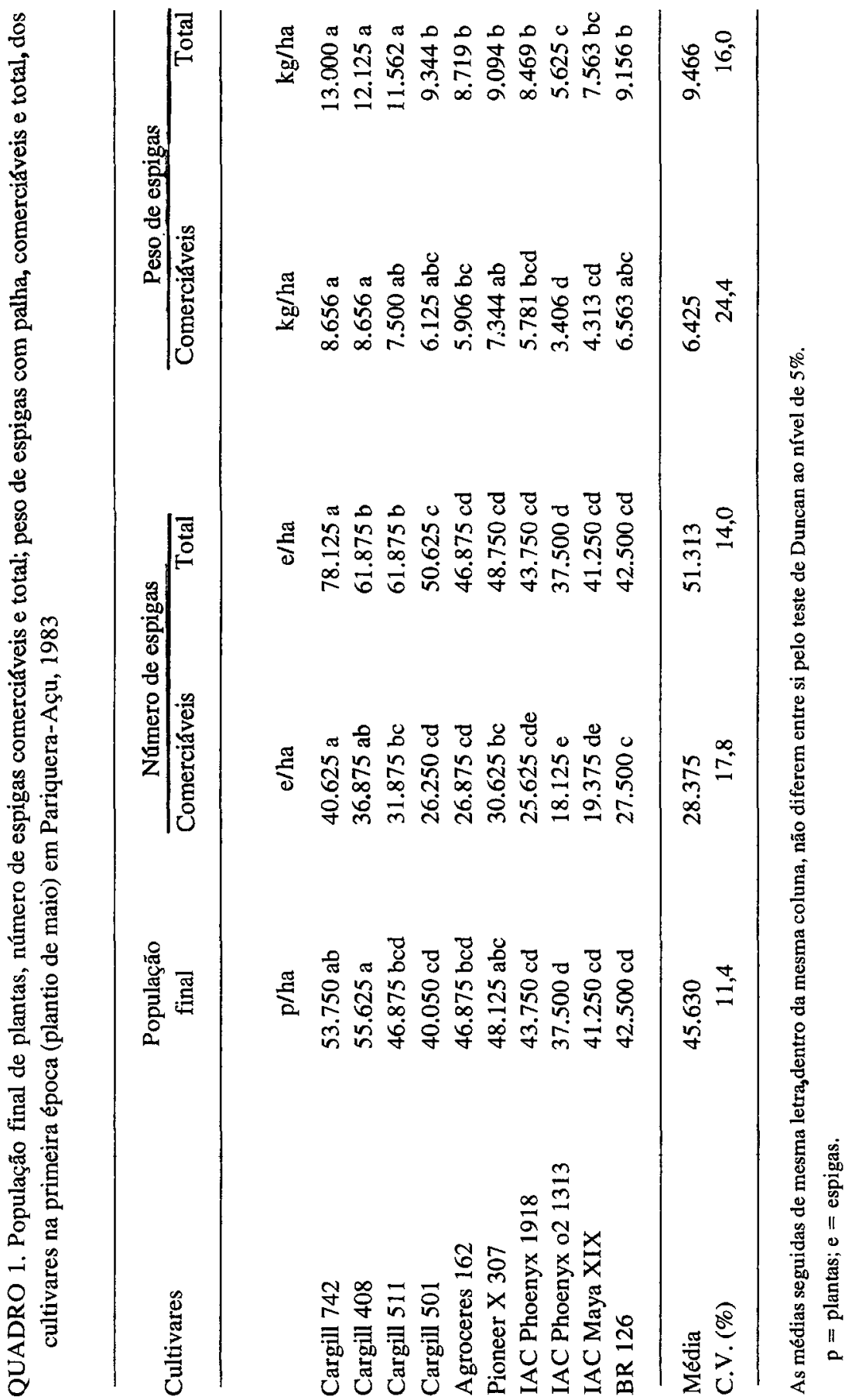




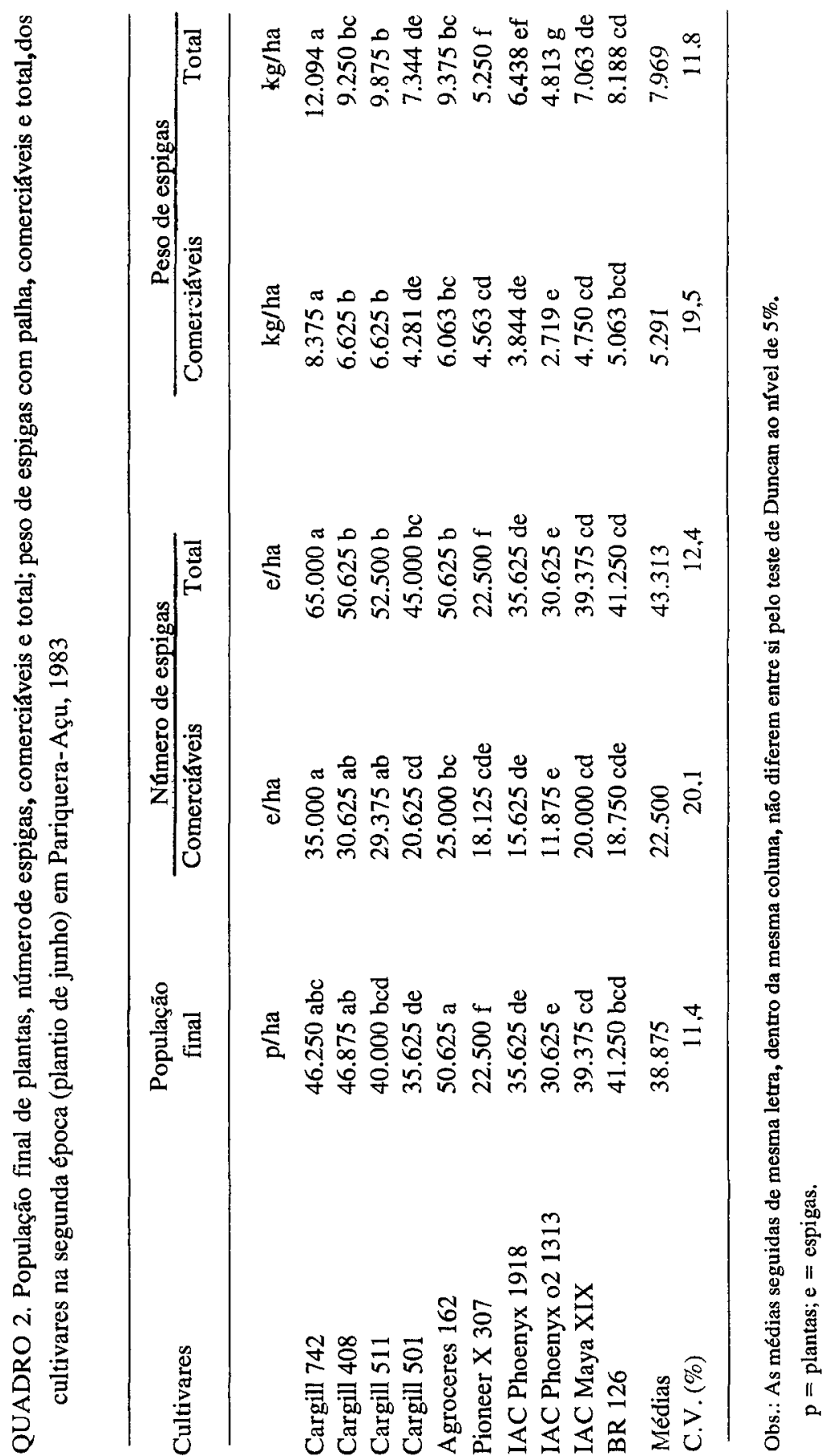


O plantio de excesso de sementes deve ter minimizado os efeitos das diferenças de germinação e vigor das sementes no estande. Outros fatores - tratamento com fungicida, adaptação a condiçōes de alta umidade e baixa temperatura, resistência a doenças e pragas - podem ter contribuído para diferenciar o estande final dos cultivares. Segundo CARVALHO \& NAKAGAWA (1980), o tratamento com fungicida pode ter efeito no estande, principalmente em condições de baixa temperatura durante a geminação. Apenas as sementes dos cultivares das fimas Agroceres, Cargill e Pioneer estavam tratadas com fungicidas: de modo geral, observou-se maior estande nos seus cultivares em relação aos do IAC e da EMBRAPA, cujas sementes não foram tratadas.

No tocante à produção em número e peso de espigas total, nas duas épocas, foram detectadas diferenças estatísticas entre cultivares, devido principalmente às variaçōes na população de plantas e maior prolificidade dos cultivares da Cargill. O Cargill 742 foi o mais prolífico, superando a todos no total de espigas, nas duas épocas, e na produção em peso na segunda época. A diferença de produtividade entre épocas parece estar correlacionada positivamente à variação observada no estande. Quanto à produção de espigas comerciáveis, houve uma pequena alteraçăo no comportamento dos cultivares em relação ao observado na produção total. Devido ao baixo rendimento de espigas comerciáveis, pode-se concluir que a produção não foi limitada pelo estande final, à exceção da produção do Pioneer X 307 na segunda época. A maior produção em magnitude, quanto ao número de espigas comerciáveis, foi a do Cargill 742, não diferindo, estatisticamente, do Cargill 408 nas duas époças, e do Cargill 511 na segunda. A produção da segunda época foi menor, correspondendo a 79 e $82 \%$ da primeira, respectivamente, para número e peso de espiga comerciável. A menor produtividade no segundo plantio pode ser devida a maior incidência de pragas e doenças, acarretando menor rendimento de espigas comerciáveis.

Os resultados da análise conjunta de variância das duas épocas, apresentados no quadro 3 , mostram que houve efeito significativo de época e cultivar para todas as caracteristicas analisadas, com exceção do indice de espigas, onde o valor de $F$ não foi significativo para época, e do peso médio, em que não houve significância para cultivar. A interaçāo "época x cultivar" só foi significativa para o estande final e número total de espigas. $O$ desdobramento dessa interação para 0 estande acusou significância da interação dos cultivares Pioneer X 307, Cargill 408, IAC Phoenyx 1918 e Cargith 742, com as épocas, havendo diminuição acentuada da população de plantas na segunda época para esses cultivares. Em relação ao número total de espigas, o mesmo fato ocorreu para os mesmos cultivares mais o Cargill 511, com exceção do IAC Phoenyx 1918.

A. produtividade de espigas comerciáveis, em número e peso, na média das duas épocas (Quadro 4), em magnitude foi maior para o cultivar Cargill 742, que não diferiu estatisticamente apenas do Cargill 408, que, por sua vez, não sé 
diferenciou do Cargilt511, e este do Agroceres 162 em número e peso, e do Pioneer X 307 e BR 126 em peso. O Agroceres 162, tradicionalmente utilizado para produção de milho verde, foi superior apenas ao IAC Phoenyx o2 1313 quanto ao número e peso, e ao IAC Maya XIX para o número de espigas comerciáveis. Em relação ao tipo do cultivar, os mais produtivos, em ordem decrescente, foram: hibridos simples, híbridos duplos, variedades e híbridos intervarietais.

QUADRO 3. Resultado do teste $\mathrm{F}$ da análise conjunta dos dados da primeira e segunda época, para população final de plantas; número de espigas, comerciáveis e total; peso de espigas com palha, comerciáveis e total; índice e peso médio de espigas comerciáveis

\begin{tabular}{|c|c|c|c|c|c|c|c|c|}
\hline \multirow[b]{2}{*}{ Causas de variação } & \multirow[b]{2}{*}{ G.L. } & \multirow{2}{*}{$\begin{array}{l}\text { Populaçāo } \\
\text { final }\end{array}$} & \multicolumn{2}{|c|}{ Número de espigas } & \multicolumn{2}{|c|}{ Peso de espigas } & \multicolumn{2}{|c|}{ Espiga comerciável } \\
\hline & & & Comereifiveis & Total & Comerciáveis & Total & Indice & Peso médio \\
\hline \multicolumn{2}{|c|}{ Repetiçāo dentro de época 6} & $*$ & * & * & ns & * & ns & ns \\
\hline Epoca (E) & 1 & ** & *** & ** & $* *$ & *** & ns & * \\
\hline Cultivares $(C)$ & 9 & $* *$ & ** & ** & $* *$ & ** & $* *$ & ns \\
\hline $\mathrm{E} \times \mathrm{C}$ & 9 & $*$ & ns & $* *$ & ns & ns & ns & ns \\
\hline Residuo médio & 54 & & & & & & & \\
\hline C.V. $(\%)$ & & 11,7 & 18,8 & 13,4 & 22,7 & 14,5 & 19,7 & 11,3 \\
\hline
\end{tabular}

*, ** Significativos, respectivamente, aos nfveis de 5 e 1\%, pelo teste $F$.

Os cultivares também apresentaram diferenças quanto ao ciclo, resistência a Helminthosporium turcicum e índice de espigás. Os hibridos da Cargill foram os mais precoces, com ciclo do plantio à colheita em torno de 112 e 113 dias, e, à exceção do Cargill 501, foram os menos atacados por $H$. turcicum. $O$ índice de espigas comerciáveis foi baixo comparado a dados anteriores (ISHIMURA et alii, 1984), sendo maior para o Cargill 742 , sem se diferenciar do Cargill 408, Cargill 511 e Pioneer $X 307$. O IAC Phoenyx o2 1313, que teve a menor população de plantas na média das duas épocas, apresentou o menor indice de espigas, não diferindo estatisticamente do IAC Maya XIX, IAC Phoenyx 1918 e BR 126.

A produtividade obtida nas duas épocas foi baixa em comparação a resu!tados de ISHIMURA et alii (1984), em plantio de julho no mesmo local, e aos reportados por COUTO et alii (1984), em plantios de maio e junho em Sete Lagoas, MG. A menor produtividade provavelmente se deva às condiçōes climáticas atipicas que ocorreram durante a fase de desenvolvimento do milho. 
QUADRO 4. Médias da produtividade em número, peso, índice e peso médio de espigas comerciáveis das duas épocas de plantio; médias das notas de avaliaçāo da incidência de Helminthosporium turcicum na segunda Época, e ciclo (do plantio à colheita) dos cultivares das duas Épocas, em Pariquera-Açu, 1983

\begin{tabular}{|c|c|c|c|c|c|c|}
\hline \multirow[b]{2}{*}{ Cultivares } & \multicolumn{4}{|c|}{ Espigas comerciáveis } & \multirow{2}{*}{$\begin{array}{l}\text { Incidência } \\
H . \text { turcicum }\end{array}$} & \multirow{2}{*}{$\begin{array}{l}\text { Ciclo } \\
\text { Epocas } \\
1=2\end{array}$} \\
\hline & Número & Peso & fndice & $\begin{array}{c}\text { Peso } \\
\text { medio }\end{array}$ & & \\
\hline & e/ha & $\mathrm{kg} / \mathrm{ha}$ & & $\mathbf{g}$ & nota $\left({ }^{(1)}\right.$ & dias \\
\hline Cargill 742 & $37.813 \mathrm{a}$ & $8.516 \mathrm{a}$ & $0,76 \mathrm{a}$ & 226 & 2,4 & 113-112 \\
\hline Cargill 408 & $33.750 \mathrm{ab}$ & $7.641 \mathrm{ab}$ & $0,65 a b c$ & 224 & 3,0 & 113-112 \\
\hline Cargill 511 & $30.625 b c$ & $7.063 b c$ & $0,71 a b$ & 229 & 3,0 & 113-112 \\
\hline Cargill 501 & $23.438 \mathrm{de}$ & $5.203 \mathrm{de}$ & 0,62 bcd & 222 & 4,3 & $113-112$ \\
\hline Agroceres 162 & $25.938 \mathrm{~cd}$ & $5.985 \mathrm{~cd}$ & $0,54 \mathrm{~cd}$ & 231 & 3,9 & $127-118$ \\
\hline Pioneer X 307 & $24.375 \mathrm{de}$ & $5.954 \mathrm{~cd}$ & $0,73 \mathrm{ab}$ & 251 & 4,4 & $117-112$ \\
\hline IAC Phoenyx 1918 & $20.625 \mathrm{de}$ & $4.813 \mathrm{de}$ & $0,51 \mathrm{de}$ & 236 & 4,1 & $127-124$ \\
\hline IAC Phoenyx o2 1313 & $15.000 \mathrm{f}$ & $3.063 \mathrm{e}$ & $0,44 \mathrm{e}$ & 211 & 4,8 & $127-124$ \\
\hline IAC Maya XIX & 19.688 ef & $4.532 \mathrm{de}$ & $0,49 \mathrm{e}$ & 229 & 3,8 & $127-124$ \\
\hline BR 126 & $23.125 \mathrm{de}$ & $5.813 \mathrm{~cd}$ & 0,55 cde & 254 & 3,8 & $127-118$ \\
\hline Média & 25.438 & 5.858 & 0,60 & 231 & 3,8 & \\
\hline C.V. (\%) & 18,8 & 22,7 & 19,7 & 11,3 & & \\
\hline
\end{tabular}

Obs:: As medias seguidas de mesma letra, dentro da mesma coluna, nôo diferem entre si pelo teste de Duncan ao nivel de $5 \%$.

(1) Segundo a cecala de avaliaçăo de ELLIOT \& JENKINS (1946), para $H$. turciczm, variando de 0 (sem infecçaso) a 5 (grande número de lesōes en todas as folhass).

e espigas.

No quadro 5, observa-se que a precipitação pluvial de maio, junho e setembro de 1983 foi maior que a ocorrida no mês mais chuvoso com base na média de 17 anos. $O$ excesso de umidade do solo, aliado à ocorrência de baixa temperatura e menor insolação naqueles meses, e de seca em agosto prejudicaram o desenvolvimento do milho, limitando principalmente a produção de espigas comerciáveis.

O rendimento dessas espigas em sacos de $30 \mathrm{~kg}$, e os valores da receita bruta, na primeira e segunda época, encontram-se no quadro 6 . Considerando a estimativa do custo operacional da cultura de milho em 1983, $\operatorname{Cr} \$ 250.000 /$ ha (PROGNÓSTICO, 1983/84), observa-se que todos os cultivares, à exceção do IAC Phoenyx o2 1313, na segunda época, apresentaram valores da receita bruta acima do custo operacional. No plantio da primeira época, os rendimentos foram maiores para todos os cultivares, à exceção do IAC Maya XIX, que teve maior produção e receita no plantio da segunda época. O 'Cargill 742 ' superou a receita do 'Agroceres 162' em cerca de $\mathrm{Cr} \$ 250.000 /$ hectare nas duas épocas, o que justifica a sua recomendação, apesar do maior custo de sua semente, por se tratar de híbrido simples. 
QUADRO 5. Dados climśticos (temperaluta média, precipitaçáo e insolaçáo) coletndea na Esılaçáo Experimental de Pariquera-Açu, media de 17 anos (1966-1982) e de 1983

\begin{tabular}{|c|c|c|c|c|c|c|}
\hline \multirow[b]{2}{*}{ Meses } & \multicolumn{3}{|c|}{ I966 a 1982} & \multicolumn{3}{|c|}{1983} \\
\hline & $\begin{array}{l}\text { Temperatura } \\
\text { media }\end{array}$ & Precipitaç̧̧o & Insoleḉَ̧̧o & $\begin{array}{l}\text { Temperatura } \\
\text { m\&dia }\end{array}$ & Precipitaçăo & Insolaça \\
\hline & ${ }^{\circ} \mathrm{C}$ & $\mathbf{m m}$ & hores & ${ }^{\circ} \mathrm{C}$ & $m n ı$ & horas \\
\hline Janeiro & 24,2 & 215,4 & 162,7 & 25,1 & 276,6 & 181,8 \\
\hline Fevereiro & 24,6 & 201,3 & 169,0 & 25,1 & 184,4 & 120,3 \\
\hline Março & 23,8 & 194,0 & 162,3 & 23,3 & 519,2 & 126,8 \\
\hline Abril & 21,1 & 107,2 & 166,2 & 22,0 & 118,6 & 89,2 \\
\hline Maio & 19,4 & 85,0 & 166,2 & 20,6 & 296,4 & 55.4 \\
\hline Junho & 17.9 & 75,8 & $14 c, 4$ & 16,5 & 236,6 & 79,7 \\
\hline Julho & 17,3 & 68,1 & 147,2 & 17,2 & 67,0 & 95,6 \\
\hline Agosto & 17,6 & 61,8 & 129,7 & 17,6 & 7,4 & 145,0 \\
\hline Setembro & 18,4 & 88,2 & 105,4 & 16,9 & 250,8 & 44,6 \\
\hline Outubro & 19,9 & 131,8 & $1 \mathrm{i} 7,2$ & 20,2 & 105,4 & 79,3 \\
\hline Noverntro & 21,7 & 130,6 & 135,4 & 23,1 & 166,2 & 186,3 \\
\hline \multirow[t]{2}{*}{ Dezemt ro } & 23,4 & 163,2 & 144,9 & 24,0 & 196,3 & 155,6 \\
\hline & 20,8 & 1522,4 & 1746,6 & 21,0 & 2020,7 & 1359,6 \\
\hline
\end{tabular}

Fonte: Seglo de Ctimntologin A grioole - IAC.

QUADRO 6. Rendimento de espigas comerciáveis (em sacos de 30kg), e valores da receita bruta (considerando o preço médio pago na CEASA de São Paulo por ocasiāo da cotheita) na primeira e segunda época de plantio, em Pariquera-Açu, 1983

\begin{tabular}{|c|c|c|c|c|}
\hline \multirow[b]{2}{*}{ Cultivares } & \multicolumn{2}{|c|}{ 1: epoca } & \multicolumn{2}{|c|}{$2=\varepsilon_{\text {poca }}$} \\
\hline & Produçāo & Receita & Produçāo & Receita \\
\hline & sacos/ha & Cr\$/ha & sacos/ha & Cr\$/ha \\
\hline Cargill 742 & 288,5 & 793.952 & 279,2 & $790.694(1)$ \\
\hline Cargill 408 & 288,5 & 793.952 & 220,8 & $625.305\left({ }^{1}\right)$ \\
\hline Cargill 511 & 250,0 & 688.000 & 220,8 & $625.305(1)$ \\
\hline Cargill 501 & 204,2 & 561.958 & 142,7 & $404.126(1)$ \\
\hline Agroceres 162 & 196,9 & 541.868 & 202,1 & $534.150(2)$ \\
\hline Pioneer X 307 & 244,8 & 673.689 & 152,1 & $430.747\left(^{1}\right)$ \\
\hline IAC Phoenyx 1918 & 192,7 & 530.310 & 128,1 & $338.568(2)$ \\
\hline IAC Phoenyx o2 1313 & 113,5 & 312.352 & 90,6 & $239.455\left({ }^{2}\right)$ \\
\hline IAC Maya XIX & 143,8 & 395.737 & 158,3 & $418.386\left({ }^{2}\right)$ \\
\hline BR 126 & 218,8 & 602.137 & 168,8 & $446.138(2)$ \\
\hline Média & 214,2 & 589.478 & 176,4 & 485.287 \\
\hline
\end{tabular}

Preço médio do saco de 30kg, CEASA-SP: Cr\$2.752 na I" epoca e Cr\$2.832 ( $\left.{ }^{1}\right)$ e Cr\$2.643 (2) na segunda Epoca.

Estimativa do custo operacional da cultura de milho em 1983/84, dado pelo IEA (Prognóstico Agrícola 83/84): Cr $\$ 250.000 / \mathrm{ha}$. 


\section{CONCLUSÕES}

Os cultivares se diferenciaram quanto à população final de plantas, indice de espigas, resistência a Helminthosporium turcicum, ciclo do plantio à colheita e produtividade.

O híbrido simples Cargill 742 , devido a sua maior uniformidade, resistência a Helminthosporium turcicum e prolificidade, teve a maior produtividade em número e peso de espigas comerciáveis, equiparando-se apenas ao híbrido duplo Cargill 408, que, por sua vez, não diferiu do Cargill 511. Este último não diferiu do Agroceres 162 em número e peso, e do Pioneer X 307 e BR 126 em peso.

As condiçōes climáticas foram atípicas, desfavoráveis à cultura do miIho, provocando baixo nivel de produtividade, embora ainda economicamente viável.

\section{SUMMARY \\ EVALUATION OF CORN CULTIVARS FOR EAR PRODUCTION AT GRAIN MILK STAGE}

Ten dent-corn cultivars were evaluated in two planting dates (May and June) at the Pariquera-Açu Experiment' Station, State of São Paulo, Brazil, in order to identify the best materials for ear production at grain milk stage. The following characteristics were studied: final stand, number of total ears and commercial ears type, weight of ears with husk, ear index, average weight of commercial ears, plant cycle and plant reaction to natural infection of Helminthosporium turcicum. Among the cultivars tested, statistically significant differences were obtained for final stand, ear index, plant cycle, yield and plant resistance to $H$. turcicum. The corn cultivars Cargill 408 and Cargill 742 were the most productive, and as compared to Agroceres 162, they matured earlier, yielded higher, showed higher ear index and were less infected by $H$. turcicum. Despite the atypical and unfavorable local season conditions for the corn crop, the relatively low productivity was still considered profitable for ear production harvested at grain milk stage.

Index terms: Green corn, cultivars, grain milk stage.

\section{REFERÊNCIAS BIBLIOGRÁFICAS}

BOLETIM INFORMATIVO ANUAL. São Paulo, CEAGESP, 1983.

CARVALHO, N.M. \& NAKAGAWA, J. Sementes: ciência, técnologia e produção. Campinas, Fundação Cargill, 1980. 326p. 
COUTO, L.; COSTA, E.F. da; VIANA, R.T. \& SILVA, M.A. Produçāo de milho verde, sob irrigação. Sete Lagoas, EMBRAPA, CNPMS, 1984. 4p. (Pesquisa em andamento, 3)

ELLIOT, C. \& JENKINS, M. Helminthosporium turcicum leaf blight of corn. Phytopathology, 36:661-666, 1946.

ISHIMURA, I.; SAWAZAKI, E.; IGUE, T. \& NODA, M. Práticas culturais na produtividade de milho-verde. Pesquisa Agropecuária Brasileira, Brasilia, 19(2):201-206, 1984.

PROGNÓSTICO. São Paulo, Instituto de Economia Agrícola, v.12, $1983 / 84$.

SAWAZAKI, E.; POMMER, C.V. \& ISHIMURA, I. Avaliação de cultivares de milho para utilização no estádio de verde. Ciência e Cultura, São Paulo, 31(2):1297-1302, 1979. 